\title{
Ann Arbor Stage II Childhood Lymphoblastic Lymphoma
}

National Cancer Institute

\section{Source}

National Cancer Institute. Ann Arbor Stage I/ Childhood Lymphoblastic Lymphoma. NCI

Thesaurus. Code C9057.

Stage II: Disease extent is limited to a single tumor with regional node involvement, 2 or more tumors or nodal areas involved on one side of the diaphragm, or a primary gastrointestinal tract tumor (completely resected) with or without regional node involvement (from PDQ). 